\title{
Effect of Nutrition Education Programme on Food-Related-Knowledge and Attitudes of Literate Women in Pankshin Community, Nigeria
}

\author{
Audu Andrew Jatau \\ Department of Health and Physical Education \\ Federal College of Education, Pankshin, Nigeria
}

\section{Doi:10.5901/mjss.2013.v4n16p35}

\begin{abstract}
The study investigated the effect of nutrition education programme on food-related-knowledge and attitudes of literate women in Pankshin community. The non-randomized control group pretest posttest quasi-experimental design was employed for the study. The instruments for data collection were a self developed 53 items nutritional knowledge and attitude questionnaire (NKAQ) and 24 content 12 weeks unit plans. The findings of the study showed that there was statistical significant difference between the mean scores of the nutritional knowledge of women exposed to nutrition education programme (NEP) and those not exposed to NEP. There was statistical significant difference between the mean scores of the nutritional attitudes of the women exposed to NEP and those not exposed to NEP. Level of education has no significant influence on the nutritional attitudes of the women. Age has no significant influence on the nutritional attitudes of the women. Based on these findings, suggestions were proffered on ways to curtail the problems of nutritional disorders
\end{abstract}

Keywords: Effect, nutrition education programme, knowledge and attitudes

\section{Introduction}

Nutrition education is one of the effective intervention strategies for bringing about nutritional knowledge, attitudinal and behavioral change in the individual. Nutrition education is one of the effective means of alerting of individuals particularly women and communities of the need for nutrition improvement. It is the step towards improving food habits (Devadas, Chandrasekhar \& Vasamthanmani, 1975).

National food and nutrition policy in developed and developing countries on realizing the increasing rate of nutritional disorders emphasize the improvement of the quality of its citizens by striving to stimulate and sustain the production and consumption of more nutritious foods, promote proper food habits and healthy lifestyles, reduce the prevalence of protein energy malnutrition (PEM), reduce the prevalence of micronutrient deficiency particularly vitamin $A$; iron and iodine among vulnerable groups, reduce over-consumption of certain nutritients particularly fats, sodium, and alcohol (Stuart \& Acherbergh, 2004). Consequent upon this policy, nutrition education programmes are now recognized as the primary form of intervention in national food and nutrition programme.

The ultimate goal of nutrition education according to leverton (1974), is to aid individual to effectively apply nutritional knowledge, attitudes beliefs and practices and modify their diets. In line with leverton's submission, lewis (1976) posited that the goal of nutrition education is to produce nutritionally sound decision makers who are motivated, knowledgeable, skilled and willing to choose proper nutrition alternative. A well planned and well delivered nutrition education programme targeted at women may produce women who are motivated, knowledgeable, and skilled and who can be empowered to make informed decisions on nutritional issues.

Women should be the important target group in any nutrition education programmes because the maintenance of adequate health particularly of infants and children is a critical maternal role. This is because 
women are a crucial link between the family and the health care system and in addition, they produce, prepare and serve food and maintain the environment. Similarly, women are the household food securities in many communities (United Nation Children Fund, 1995). This justifies the choice of women as the primary target group for the present study.

\section{Purpose of the Study}

The purpose of this study was to determine the effect of nutrition education programme on food- relatedknowledge and attitudes of women in Pankshin community. Specifically, the objectives of the study were to:

1. Determine the effect of nutrition education programme (NEP) on the nutritional knowledge of women exposed to NEP and those not exposed to NEP in Pankshin community.

2. Ascertain the effect of NEP on the nutritional attitudes of women exposed to NEP and those not exposed to NEP in Pankshin community.

3. Determine the influence of level of education on the nutritional attitudes of women in Pankshin community.

4. Ascertain the influence of age on the nutritional attitudes of women in Pankshin community.

\section{Research Questions}

To guide the study, the following research questions were posed:

1. What is the effect of nutrition education programme (NEP) on the nutritional knowledge of women exposed to nutrition education programme (NEP) and those not exposed to NEP in Pankshin community?

2. Is there any effect of NEP on the nutritional attitudes of women exposed to NEP and those not exposed to NEP in Pankshin community?

\section{Hypotheses}

The following null hypotheses were formulated and tested at.05 level of significance.

1. There is no statistical significant difference in the effect of NEP on the nutritional knowledge of women exposed to NEP and those not exposed to NEP in Pankshin community.

2. There is no statistical significant difference in the effect of NEP on the nutritional attitudes of women exposed to NEP and those not exposed to NEP in Pankshin community.

3. There is no statistical significant difference in the influence of level of education on the nutrition attitudes of women in Pankshin community.

4. There is no statistical significant difference in the influence of age on nutritional attitude of women in Pankshin community.

\section{Methods}

In order to achieve the purpose of this study, the quasi-experimental design was employed. Specially, the non-randomized pre-test post-test design or non- equivalent design was adopted in this study. The short hand notation of the non-equivalent design has been presented by Fisher, laing, Stockel and Townsend (1998) thus:

$$
\begin{array}{ll}
\underline{0}_{1}-\underline{x}-\underline{03} \\
0_{2}-\quad 04
\end{array}
$$

The population for the study consisted only literate women in Pankshin community. The sample for the study at the initial stage consisted of only 181 literate women. Of the 181 literate women who constituted the 
sample frame, 15 of them did not continue the nutrition education lessons and therefore dropped out leaving 166 participants. The remaining 166 literate women formed the sample frame for the present study.

The researcher randomly selected two sub-communities namely new lay-out and Yimtul. Out of the two sub-communities that were selected one (New lay-out) was assigned to the experimental group and the other (Yimtul was assigned to the control group. These two sub-communities were far apart from each others so as to avoid interactions which could be a threat to the study.

A 72 item nutritional knowledge and attitude questionnaire (NKAQ) was categorized into three sections -A B and C. Section A contained two socio-demographic variables- age and level of education. Section B contained items with response options of true or false which measured the nutritional knowledge of women. Section C contained items with response options of strongly agree, agree, disagree and strongly disagree which measured nutritional attitudes of the women.

The face and content validity of the instruments were obtained through the judgment of five experts from the University of Nigeria Nsukka. Based on the inputs, corrections and suggestions made by the experts, the final copy of the questionnaire and the contents of the planned NEP were produced. A reliability index of .75 of the instrument was established using test-retest method.

The participants were pre-tested using nutritional knowledge and nutritional attitudes scores questionnaire. This instrument was administered to the women with the assistance of three trained research assistants and the scores were recorded before the treatment started.

Women or participants assigned to the experimental group were taught for a period of 12 weeks using the planned component of NEP while the participants in the control group were taught not using the same content of NEP; rather they were taught using the content or components of personal health.

At the end of the $12^{\text {th }}$ week after the subjects in the experimental group had been treated the researcher and the three trained research assistants distributed the same developed copies of the questionnaire forms to the subjects both in the experimental and control groups. The filled copies of the questionnaire forms were collected back on the spot, recorded and used for the study.

\section{Results}

The findings of the study are presented below according to the research questions and hypotheses posed.

Table 1: Effect of NEP on the Nutritional Knowledge of Women Exposed to NEP and Those not Exposed to NEP in Pankshin Community

\begin{tabular}{cccccc}
\hline Group & No & \multicolumn{2}{c}{ Pretest } & \multicolumn{2}{c}{ Pottest } \\
\hline & & $\overline{\mathrm{x}}$ & $\mathrm{SD}$ & $\overline{\mathrm{x}}$ & $\mathrm{SD}$ \\
Experimental & 92 & 16.47 & 4.13 & 22.48 & 2.96 \\
Control & 74 & 13.98 & 4.47 & 15.68 & 4.98 \\
\hline
\end{tabular}

Table 1, reveals that the post test of the nutritional knowledge of women exposed to NEP $(\bar{x}=22.48)$ is higher than the posttest of the women not exposed to NEP $\bar{x}=15.68)$. This represents a 6.8 mean again score which is attributed toz the effect of NEP on the nutritional knowledge of the women exposed to NEP. Further more, the table reveals that the mean score of the posttest of the women exposed to NEP is higher than the mean score of the same experimental group when they were yet to be exposed to NEP (pretest $\bar{x}=16.47<$ posttest=22.48). The 6.01 mean score differential is consequent upon the effect of NEP on the nutritional knowledge of the women exposed to NEP.

Table 2: Effect of NEP on the Nutritional Attitudes of Women Exposed to NEP and Those Not Exposed to NEP in Pankshin Community. 


\begin{tabular}{cccccc} 
Group & No & Pretest & \multicolumn{3}{c}{ Posttest } \\
\hline & & $\overline{\mathrm{X}}$ & SD & $\overline{\mathrm{X}}$ & SD \\
Experimental & 92 & 37.18 & 6.28 & 45.36 & 5.83 \\
Control & 74 & 35.24 & 7.82 & 36.36 & 7.45 \\
\hline
\end{tabular}

Table 2 indicates that the grant posttest of the nutritional attitudes of women exposed to NEP is higher than the posttest of the women not exposed to NEP (Experimental $\bar{x}=45.36>$ control $\bar{x}=36.36$ ). This represents 9 mean gain score which is adduced to the effects of NEP. In the same vein, the table shows that the posttest mean score of the women exposed to NEP is higher than the mean score of the same group of women when they were yet to be exposed to NEP ( posttest $\bar{x}=45.36>$ pretest $\bar{x}=37.18$ ). The 8.18 mean score differential indicates NEP's effect on the nutritional attitudes of the women exposed to NEP

Table 3: Summary of ANCOVA Difference Between the Mean Score of the Nutritional Knowledge of Women Exposed to NEP and Those not Exposed to NEP

\begin{tabular}{lcccccl}
\hline Source of Variation Sum of Squares & Df & Mean Square Level of Significance F.cal F tab Decision \\
\hline Covariates & 141.551 & 1 & 141.551 & & 9.344 & \\
Pretest & 141.551 & 1 & 141.551 & 9.344 & \\
Main effect & 1481.926 & 1 & 1481.926 & 97.82 & \\
Group & 1481.926 & 1 & 1481.926 & .05 & 97.823 .8 Rejected \\
Explained & 2037.916 & 2 & 1018.958 & & 67.62 & \\
Residual & 2469.289 & 163 & 15.149 & & & \\
Total & 4057.205 & 165 & 27.316 & & & \\
\hline
\end{tabular}

Result in table 3 show that the $\mathrm{F}$ calculated value of $97-82$ with 1 and 165 degrees of freedom is greater than the $F$ table value of 3.84 at .05 level of significance $(F$ cal. $=97.82>F$-tab $=3.84, P>.05)$. This implies that there was significant difference between the mean scores of the nutritional knowledge of the women exposed to NEP and those not exposed to NEP. The difference observed was not in fact due to chance, but the effect of the NEP on the nutritional knowledge of the women exposed to NEP.

Table 4: Summary of ANCOVA Difference Between the Mean Score of the Nutritional Attitude of Women Exposed to NEP and Those not Exposed to NEP

\begin{tabular}{|c|c|c|c|c|c|}
\hline Source of Variatior & n Sum of Squares & Df & Mean Square & Level of Significance & F.cal F tab Decision \\
\hline Covariates & 172.9051 & 1 & 172.905 & & 4.03 \\
\hline Pretest & 172.9051 & 1 & 172.905 & & 4.03 \\
\hline Main effect & 3175.265 & 1 & 3175.265 & & 74.11 \\
\hline Group & 3175.265 & 1 & 3175.265 & .05 & 74.11 3.84 Rejected \\
\hline Explained & 3498.352 & 2 & 1749.176 & & 40.82 \\
\hline Residual & 6983.678 & 163 & 42.845 & & \\
\hline Total & 10482.030 & 165 & 63.527 & & \\
\hline
\end{tabular}

Results in Table 4 show that the F- calculated value of 74.11 with 1 and 165 degrees of freedom is greater than the $F$ table value of .05 level of significance ( $F$ - cal. 74.11 $>F$ tab.= 3.84,p>.05). This implies that there was significant difference between the mean scores of the nutritional attitudes of the women exposed to NEP and those not exposed to NEP. The difference observed was not in fact due to chance, but the effect of the NEP on the nutritional attitudes of the women exposed to NEP. 
Table 5: Summary of ANCOVA on the Difference in the Influence of Level of Education on the Nutritional Attitudes of Women in Pankshin Community

\begin{tabular}{lcccccl}
\hline \multicolumn{1}{c}{ Source of Variation } & Sum of Squares & Df & Mean Square Level of Significance & F.cal F tab Decision \\
\hline Covariates & 121.04 & 1 & 12.014 & & 2.98 & \\
Group & 3156.315 & 1 & 3156.315 & & 77.73 & \\
Level of Education & 172.788 & 2 & 86.394 & .05 & 2.12 & 3.0 Accepted \\
Group+ level of Education & 332.886 & 2 & 166.443 & & 4.09 & \\
Error & 6455.718 & 159 & 40.602 & & & \\
Total & 294387.00 & 166 & & & & \\
Corrected Total & 10482.030 & 165 & & & &
\end{tabular}

Table 5 reveals that the calculated $F$ value of 2.12 with 2 and 164 degrees of freedom is less than the $F$ critical value of 3.00 at 0.5 level of significance (cal. $F=2.12<T a b . F=3.00 p>.05$ ). This means that level of education has no statistical significant influence on the nutritional attitudes of the women.

Table 6: Summary of ANCOVA on the Difference in the Influence of Age on Nutritional Attitudes of Women in Pankshin Community

\begin{tabular}{lccccc}
\hline Source of Variation Sum of Squares & Df & Mean Square Level of Significance & F.cal F tab Decision \\
\hline Covariates & 151.406 & 1 & 151.406 & & 3.51 \\
Group & 2951.336 & 1 & 2951.336 & 68.51 & \\
Age & 115.378 & 2 & 57.689 & .05 & 1.33 3.00 Accepted \\
Group + Age & 24.630 & 2 & 12.315 & & .28 \\
Error & 6848.679 & 159 & 43.073 & & \\
Total & 294387.000 & 166 & & & \\
Corrected Total & 10482.030 & 165 & &
\end{tabular}

The results in table 6 indicate that the calculated $F$ value 1.33 with 2 and 164 degree of freedom is less than the table F. value of 3.00 at .05 level of significance ( cal. $F=1.33<$ tab- $F=3.00, p<.05$ ). This implies that age had no statistical significant influence on the nutritional attitudes of the women.

\section{Discussion}

The finding that there was difference between the mean scores of the nutritional knowledge of women exposed to NEP and those not exposed to NEP is heart warming. This is because the NEP which aimed at imparting nutritional knowledge to the women exposed to the programme had indeed promoted their knowledge. This implies that the NEP produced positive effect on the nutritional knowledge of the women exposed to it. This finding lends credence to the findings of Ezealigo (2000) who found that after a nutrition education programme for mothers of childbearing age the nutritional knowledge rose to 90.8 per cent representing a 10.5 percent increase in the nutritional knowledge of the subjects. This was evidenced in various aspects of the NEP such as food hygiene, purchasing of food and food selection. The finding also corresponds with the study of Samuel (2000) who found that students in the experimental group performed better in nutritional knowledge test than the students in the experimental group after introducing nutritional teaching guide. In the same vein, the finding corroborates the study of Okpoko (2001) and Glassauer et-al. (2003) each of who found that there was greater gain scores in nutritional knowledge after exposing their subjects to nutrition and health education project.

The finding that there was significant difference in the mean scores of the nutritional attitudes of women exposed to NEP and those not exposed to NEP implies that NEP played a pivotal role in promoting positive 
nutritional attitude of the women exposed to it. This finding corroborates the findings of Samuel (2000) who found that the posttest nutrition attitudinal scores for experimental group was higher than the posttest mean attitudinal scores for control group. The finding further supports the finding of Glassauer etal (2003) who found that after school Health and Nutritional project, the impact of the project influenced schools which implemented a wide range of nutrition education and other health promotion activities, and the final evaluation indeed was significant improvement in nutritional attitudes and behaviors of the participants.

The finding that NEP had promoted knowledge and positive effect of nutritional attitude of the women exposed it is a good reason for the inclusion of nutrition education programme in the nations (Nigeria) curricula in both the three tiers of education. The teaching approach of nutrition education should be devoid of passing mere information but it should be practical orientated such that it can touch the three domains of learning- psychomotor, cognitive and effective.

The finding that level of education had no significant influence on the nutritional attitudes of the women was not expected because the level of education of the women is supposed to exert positive nutritional influence on them. Interestingly, this finding corroborates that of Ogunsina and Emapkae (2003) who found that level of education had no statistical influence on the nutritional attitudes of their subjects. On the other hand, the finding negates the studies of Schumulas, Wooldcot and Esler (1984) who found that mothers with high level of education possessed positive nutritional attitudes.

The finding that age had influence on the nutritional attitudes of the women was surprising and unexpected. Age is expected to go with experience which can positively influence nutritional attitude of the women. This finding agrees with that of Beaver, Kelley and Flenner (1982) whose findings revealed that age had no statistical significant influence on the nutritional attitudes of their subjects. However, the finding is at variance with Gudam's (2002) who found statistical difference in the influence of age on the nutritional behaviors of his subjects.

\section{Conclusion and Recommendations}

Based on the finding of the study, it is concluded that there was significant difference between the mean scores of the nutritional knowledge of women exposed to NEP and those not exposed to NEP. NEP had positive effect on the nutritional knowledge of the women exposed to NEP. There was significant difference between the mean scores of the nutritional attitudes of the women exposed to NEP and those not exposed to NEP. The difference observed on the nutritional knowledge and nutritional attitudes of the women exposed to NEP and those not exposed to NEP, is not in fact due to chance, but the effect of NEP. Level of education had no statistical influence on the nutritional attitudes of the women. Age had no statistical influence on the nutritional attitudes of the women

Based on the findings of the study, the following are recommended:

1. Federal and state ministry of education should introduce the teaching of nutrition education at the three tiers of education. It is believed that what the students learnt related to nutrition education can be applied in their life time.

2. The positive effect of NEP in the improvement of nutrition knowledge, attitudes and practices should be used as a weapon by health educators, nutritionist, home economist and dietitians to convince the federal, state, local governments and non-governmental agencies to see the need for sponsoring NEP projects in community settings, school setting and work place. This would go a long way in enhancing positive nutrition behavioral change.

3. People should develop positive nutritional life styles. This can go a long way in promoting the nutritional status of the citizens. 


\section{References}

Beaver, I., Kelly, M., \& Flenners, J. (1982). Nutritional knowledge, attitude and food purchasing practices of parents. Home Economic Research Journal, II (2), 18-25

Devadas, R.P, Chandrasekhar, B., \&Vasathamani,S . (1975). Needs for nutrition education. Proceedings of Nutrition Society of India, 21 21-23.

Ezealigo, A.I. (2000). Effect of nutrition education programme on mothers of childbearing age at University of Nigeria, Nsukka Teaching Hospital, Enugu State. Unpublished M.Ed thesis, University of Nigeria, Nsukka,

Fisher, A.A., Laing, J.E., Stockel L.E, \& Townsend, J.W. (1998). Handbook for family planning operations research designs ( $2^{\text {nd }}$ ed). New York: Population.

Glassauer, P., Aldinger, C.Y.U, Sen-hai Y., Shi-change, X.,\& Tang Shu-ming, T. (2003). Nutrition as an entry point for health promoting schools: lesson from China. Food, Nutritional and Agriculture 33.27-33.

Gudam, M.B. (2002). Nutrion knowledge, beliefs and behaviours among teenage. students in Pankshin inspectorate education of Plateau State. Unpublished M. Ed Thesis, University of Nigeria Nsukka, Enugu State.

Leverton, R. (1974). What is nutrition education? Journal of American Dietetics Association 64, 17-21.

Lewis, K.J. (1976). Nutrition education in changing world. In S.S Laura (ed). Overview: Nutrition education research in the policy arena. Proceeding of the penn state conferencs. Directions for Nutrition Education Research. Pennsylvania state university, Pennsylvania, USA, July-Oct. 1980.

Ogunsina, D., \&Emapkae, G.A. (2003). Food fads and nutritional attitudes of inhabitants of Ojo, Lagos state, Nigeria. Nigerian School Health Journal, 15 (1\&2), 109-117.

Okpoko, A. (2001). Literacy education and level of food and nutrition awareness of adults. In E.U Anyakoha (ed). Research imperatives and challenges for Home Economics in Nigeria. Home Economics Association of Nigeria.

Stuart, T.H., \&Acherbergh, C. (2004). Nutrition education and communication strategies for different groups and settings. UNICEF Manila, Philippines. 
